\section{Osteoporosis School in Primary Health Care-A Pilot Study}

\author{
Ann-Charlotte Grahn Kronhed ${ }^{1,2^{*}}$ \\ ${ }^{1}$ Rehab Väst Vadstena, Local Health Care Services in the West of Östergöt- \\ land, Sweden \\ ${ }^{2}$ Division of Physiotherapy, Department of Medical and Health Sciences, \\ Linköping University, Linköping, Sweden
}

\begin{abstract}
An Osteoporosis school was introduced as a pilot study in a Swedish primary health care center. Women aged 50 years and over with healed fragility fractures were asked to participate. The aim was to increase awareness amongst the participants and to advise them about life-style and fall prevention strategies to prevent a secondary fragility fracture. The Osteoporosis school was scheduled to once a week for eight weeks and included theory and exercise training sessions. Eleven women with mean age 74 years participated. Clinical tests such as back straightening test and balance tests were performed, pain was estimated by the visual analogue scale, and health-related quality of life was measured by the SF-36 questionnaire. Straightening of the back improved $0.6 \mathrm{~cm}(p<0.05)$, worst estimated pain decreased from 5.8 to $4.0(p<0.05)$, and the SF-36 bodily pain domain improved $(p<0.05)$. The participants completed an average of 7 out of 8 sessions. The exercise training sessions were the most appreciated part of the program.

Keywords: Education; Fragility fracture; Older adults; Osteoporosis;
\end{abstract} Women

\section{Background}

Osteoporosis is a major growing public health problem and affects more than 200 million people worldwide [1]. Osteoporosis is defined as "a disease characterised by low bone mass and microarchitectural deterioration of bone tissue, leading to enhanced bone fragility and a consequent increase in fracture risk" [2,3]. Sweden has one of the highest incidences of osteoporotic fractures in the world with about 107,000 osteoporosis-related fractures each year [4,5]. The lifetime risk for a hip, spine or forearm fracture at the age of 50 is estimated at $46 \%$ for women, and $22 \%$ for men, in Sweden [6]. Hip fracture is the most serious fragility fracture and means deteriorated health related quality of life and great suffering to the individual

${ }^{*}$ Corresponding author: Ann-Charlotte Grahn Kronhed, RehabVäst Vadstena, Local Health Care Services in the West of Östergötland; Division of Physiotherapy, Department of Medical and Health Sciences, Linköping University, Linköping, Sweden, Tel: +46 101048158; E-mail: lotta.grahn-kronhed@telia.com

Citation: Grahn Kronhed AC (2017) Osteoporosis School in Primary Health Care-A Pilot Study. J Orthop Res Physiother 3: 033

Received: March 31, 2017; Accepted: October 02, 2017; Published: October 16, 2017 and high costs to the society. The costs of a hip fracture have been estimated at approximately US $\$ 21000$ for the first year [7]. Accelerated bone loss due to estrogen deficiency occurs immediately after the menopause and lasts for about 10 years. About half of the loss in trabecular bone results from the menopause and about a half from the aging process [8]. Low Bone Mineral Density (BMD) is a strong risk factor for fracture. The T-score, defined by the WHO, is used for the diagnosis of low BMD measured by Dual energy X-ray Absorptiometry (DXA) equipment at the spine, hip or mid radius sites and uses a reference group of "young adult women." A T-score value of not more than 1 Standard Deviation (SD) below the mean value of peak bone mass in young adult women is defined as normal. A T-score greater than $1 \mathrm{SD}$ below the young adult mean, but less than 2.5 SDs below this value, is defined as osteopenia, and a T-score of 2.5 SDs or more below the young adult mean is defined as osteoporosis. Established (severe) osteoporosis means a T-score of 2.5 SDs or more below the young adult mean and the presence of at least one fragility fracture [3]. Some people with a fragility fracture might not be adequately treated by bone-specific drugs and might not either get any information on appropriate physical activity or fall preventive advice in the prevention of a secondary fracture. Primary health care has the main responsibility for the prevention of osteoporosis and fragility fractures, as stated by the WHO [8]. The FRAX ${ }^{\circledR}$ tool (www.shef.ac.uk/ FRAX) integrates the weight of clinical risk factors for a ten-year probability of hip fracture and major osteoporotic fracture, in persons aged 40-90 years using patient-derived clinical risk factors, with or without the inclusion of femoral neck BMD (Figure 1). A fragility fracture is usually caused by a mild to moderate trauma such as a fall from standing height or less and an osteoporotic vertebral fracture may occur after lifting an object or bending forward [9]. Considerable height loss may indicate osteoporotic vertebral fractures [10]. An increase in vertebral fracture prevalence in relation to historical height loss was previously found and the cutoff was suggested to be $6 \mathrm{~cm}$ (2.4 inches) in postmenopausal women [11].

A recent review indicated that it is unclear whether patient education is beneficial and whether it has a significant and clinically relevant impact on osteoporosis management results, and therefore requires further investigation [12].

A pilot study with an Osteoporosis school was introduced at Vadstena Primary Health Care Centre (PHCC), Sweden, focusing middle-aged and elderly women with a healed fragility fracture. The aim of the Osteoporosis school was to deliver disease-specific information to persons at risk of having a secondary fracture and to advise them about the importance of a healthy life-style and adequate physical activity, and also about ergonomic principles and fall prevention measures to prevent a secondary fracture.

\section{Materials and Methods}

\section{Participants}

Women aged 50 years and over with a healed low-energy fracture such as vertebral, hip, upper arm (humerus) or distal forearm fracture attending primary health care in the west of Östergötland, Sweden were offered to participate in an Osteoporosis school. Information on 
the start of the Osteoporosis school for the recruitment of patients was given to physicians working at primary health care centres $(n=9)$ and at Proxima orthopaedic clinic, and also to rehabilitation personnel in the West of Östergötland. A total of eighteen women were asked about participating in group activities and received information about the Osteoporosis school.

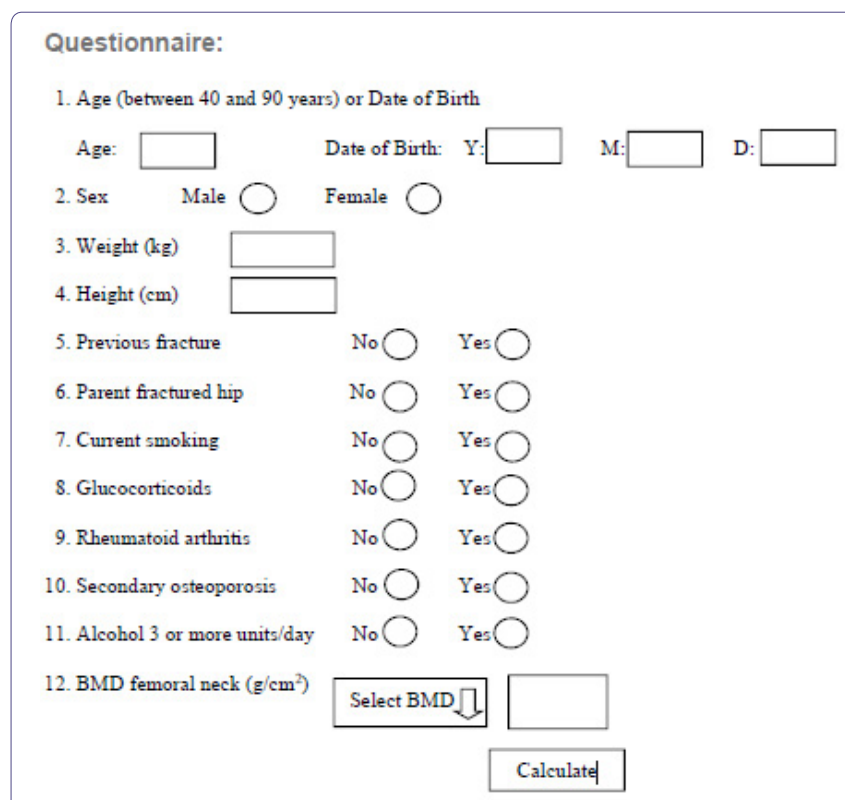

Figure 1: FRAX-Fracture Risk Assessment Tool (http://www.shef.ac.uk/ FRAX/). (For the clinical risk factors, a no or yes response is asked for. If the field is blank, then a "no" response is assumed. In patients without a BMD test, the field for BMD femoral neck should be left blank).

\section{Methods}

A questionnaire was completed at baseline concerning the presence of diseases and medications, body height and fracture occasion at adulthood, and fall events for the last year. The FRAX ${ }^{\circledR}$ tool was used for the calculation of a ten-year probability of a hip fracture and major osteoporotic fracture. Body height $(\mathrm{cm})$ was measured by a stadiometer and body weight $(\mathrm{kg})$ by a digital scale. Body Mass Index (BMI) was calculated as body weight in $\mathrm{kg}$ / (height in metres squared). The distance $(\mathrm{cm})$ between the seventh cervical vertebra (C7) and the wall was measured by a folding ruler to estimate the back-straightening ability and grade of thoracic kyphosis [13]. Measurements by clinical tests and Health-Related Quality of Life (HRQL) were performed before and after the intervention period. Jamar dynamometer was used to measure hand grip strength $(\mathrm{kg})$ of the dominant and the non-dominant hand. For standardization, the adjustable handle was set at the second position. Each test was performed three times and the best trial was counted [14]. Static balance tests were performed by tandem standing with eyes open and then closed (Sharpened Romberg), one-leg standing (right and left) with the eyes open and then closed. The one-leg standing tests were performed with the opposite foot lifted halfway up the calf of the supporting leg and arms at sides. The static balance tests were limited to a maximum of $30 \mathrm{sec}-$ onds. Timing was stopped if the supporting foot was moved from its initial position. The dynamic balance tests included tandem walking forwards heel to toe and backwards toe to heel on a line. The number of steps were counted and maximized to 15 correct steps. The static and dynamic balance tests were performed three times and the best trial was used as the final score [15]. There was also a chair rising test five times without support of the arms. This test was assessed as being successful or not successful [16]. An experienced physiotherapist performed the clinical tests.

The participants completed the generic Short Form 36 (SF-36, version I) for assessment of their HRQL. The questionnaire has good reliability and validity [17-20]. The SF-36 version 1 compromises 36 items with two to six response options according to an ordinal scale. Eight health domains were assessed: Physical Function (PF), Role Physical (RP), Bodily Pain (BP), General Health (GH), Vitality (VT), Social Function (SF), Role Emotional (RE), and Mental Health (MH) $[17,21]$. Two summary scores were calculated from these eight domains: Physical Component Summary (PCS) and Mental Component Summary (MCS) indexes using previously established methods [21]. The SF-36 items were coded, scored and summarized to derive the eight domains. The scores were transformed into a 0-100 scale. Zero indicated the worst possible HRQL and 100 the best [18]. Present pain and the worst pain were estimated by a Visual Analogue Scale (VAS) from $0-10$, where 0 indicated no pain and 10 the worst possible pain $[22,23]$.

\section{Intervention program}

The Osteoporosis school was scheduled to once a week for eight weeks. Each session lasted 90 minutes and included theory and exercise training sessions. The training started with a 10-minute warm-up phase and the exercises were individually adjusted to the participant's physical capacity. The importance of a good body posture was emphasized through the training program. The training program consisted of back extension exercises positioned on hands and knees while raising the leg and the opposite arm in a diagonal plane, isometric back extensor muscle training in a prone position (with a pillow under the stomach), facing a wall in standing position and straightening the back by simultaneously raising the arms with support against the wall, push-ups at wall bars, elastic band and dumbbells exercises, chair rising, careful knee-bending, toe-rising when standing, and also different coordination steps [24-29]. Balance exercises were tailored to the participants and were performed by different steps with different velocity and directions and also by rising exercises and by training equipment and balls $[15,30]$. The program was completed by qi-gong and relaxation exercises [31,32]. In addition, the participants were educated about adequate home-based exercises for strengthening the back and lower extremity $[24,25,33]$. The women received information that exercises such as sit-ups, bending forward and rotation of the trunk should be avoided, as these exercises may increase the risk of a vertebral compression [24,34]. After each training session, there was a coffee break followed by the educational part. Physiotherapists, occupational therapist and a nurse were responsible for the different part of the sessions. The educational themes were as follows:

1. The disease osteoporosis and its consequences - a public health problem

2. Clinical risk factors for the probability of an osteoporotic fracture (FRAX), diagnosis and treatment

3. Anatomy of the skeleton and bone structure, and also the balance system

4. Ergonomic aspects of performing daily living activities, and also adequate aid and support (orthoses) 
5. Self-management with nutritional, physical activity and fall prevention behaviour

6. Mindfulness

At the end of the intervention period the participants were offered physical activity on prescription (in Swedish $\mathrm{FaR}^{\circledR}$ ) to improve their physical activity habits [35], and they were also introduced to individual or group training program with sequence training equipment at the PHCC gymnasium [36,37].

\section{Statistical methods}

Group results are presented as Mean (M) and Standard Deviation (SD) and Median (Md) and range are also reported. Wilcoxon sign rank test was used for the analysis of change in the group, as the material was small. Significant level $\alpha$ less than $5 \%$ was considered as statistically significant. Statistica version 13 was used for the calculations.

\section{Results}

\section{Participants and drop-outs, attendance}

Eighteen women were asked about participating in the Osteoporosis school. Some preliminary participants declined the school, as they had not quite understood the information that the school meant group activities and some had also problems with transportations to and from the Osteoporosis school. Eleven women consented to the study and participated in the program. Only two of the participants were referred from primary health care centres other than the Vadstena PHCC. The participants completed an average of 7 sessions $(\mathrm{Md}=7$, range 4-8).

\section{Group characteristic}

The women were born 1921-1953 and their mean age was 74 years ( $\mathrm{SD}=9.5, \mathrm{Md}=76$ years, range 58-90), mean body height was $158 \mathrm{~cm}$ ( $\mathrm{SD}=9, \mathrm{Md}=160 \mathrm{~cm}$, range 141-169), mean body weight was $65.6 \mathrm{~kg}$ $(\mathrm{SD}=14.2, \mathrm{Md}=60 \mathrm{~kg}$, range 48-90), and mean $\mathrm{BMI}$ was $26(\mathrm{SD}=4.2$, $\mathrm{Md}=26$, range 20-32). Mean body height loss since young adult age was $5 \mathrm{~cm}(\mathrm{SD}=3.4, \mathrm{Md}=5 \mathrm{~cm}$, range $1-12)(\mathrm{p}<0.01)$.

\section{Drugs, fractures and FRAX-values}

Eight women used bone-specific drugs such as bisphosphonates, and calcium combined with vitamin D. Three women had rheumatic diseases and had used corticosteroids and three women used levaxin. Vertebral fracture was reported by six women, humerus fracture by four women, and forearm fracture by one woman. Six women reported at least one fall for the last year. FRAX mean value for the probability of a ten-year hip fracture was $21 \%(\mathrm{SD}=16, \mathrm{Md}=16 \%$, range 2-54), and FRAX mean value for the probability of a major osteoporotic fracture was $38 \%(\mathrm{SD}=16, \mathrm{Md}=39 \%$, range $13-64)$.

\section{Back straightening, chair rising, balance performance, handgrip, pain, and health-related quality of life}

The back-straightening test (C7-wall distance) was improved with about 0.6 centimetre $(p<0.05)$. Ten women were successful in the chair rising test. One woman withdrew from the rising test and another woman from the one leg balance stance tests because of worsened back pain. There was a tendency towards more correct steps in the tandem walking forwards on a line from 10.4 to 11.5 steps $(\mathrm{p}=0.068)$. The women managed to stand on one leg with eyes open for about
13 seconds. Handgrip strength did not change. Estimated worst pain decreased from 5.8 to $4.0(\mathrm{p}<0.05)$ and there was also a tendency towards decreased present pain from 4.7 till $2.8(\mathrm{p}=0.069)$ (Table 1). The SF-36 bodily pain domain improved from 36.7 to $51.3(\mathrm{p}<0.05)$ (Figure 2).

\begin{tabular}{|c|c|c|c|c|}
\hline & Base-line & Follow-up & & \\
\hline Clinical tests & Mean (SD) & Mean (SD) & $\mathbf{n}$ & $\mathbf{p}$ \\
\hline Back straightening (C7-wall) (cm) & $6.7(1.5)$ & $6.1(1.8)$ & 11 & $\mathbf{0 . 0 1 8}$ \\
\hline Handgrip dominant (kg) & $19.4(7.5)$ & $19.8(7.0)$ & 11 & 0.307 \\
\hline Handgrip non-dominant (kg) & $17.6(7.8)$ & $17.6(6.7)$ & 11 & 0.859 \\
\hline Sharpened Romberg, eyes open (s) & $23.2(11.2)$ & $25.2(9.0)$ & 11 & 0.225 \\
\hline Sharpened Romberg, eyes closed (s) & $12.4(13)$ & $11.7(12.6)$ & 11 & 0.917 \\
\hline Right leg, eyes open (s) & $12.3(11.9)$ & $13.3(12.3)$ & 10 & 0.401 \\
\hline Left leg, eyes open (s) & $14.4(14.3)$ & $12.2(10.6)$ & 10 & 0.646 \\
\hline Right leg, closed eyes (s) & $2.5(4.5)$ & $2.6(5.6)$ & 10 & 0.654 \\
\hline Left leg, closed eyes (s) & $1.4(2.3)$ & $1.4(2.3)$ & 10 & 1 \\
\hline Walking forwards (steps) & $10.4(6.9)$ & $11.5(5.9)$ & 11 & 0.068 \\
\hline Walking backwards (steps) & $8.5(6.9)$ & $9.5(6.2)$ & 11 & 0.106 \\
\hline Present pain (VAS) & $4.7(2.4)$ & $2.8(2.7)$ & 11 & 0.069 \\
\hline Worst pain (VAS) & $5.8(3.5)$ & $4.0(3.4)$ & 10 & $\mathbf{0 . 0 4 3}$ \\
\hline
\end{tabular}

Table 1: Change in the group with Mean and Standard Deviation (SD) at base-line and after the intervention period.

Significance level $\mathrm{p}<0.05$ is presented in bold.

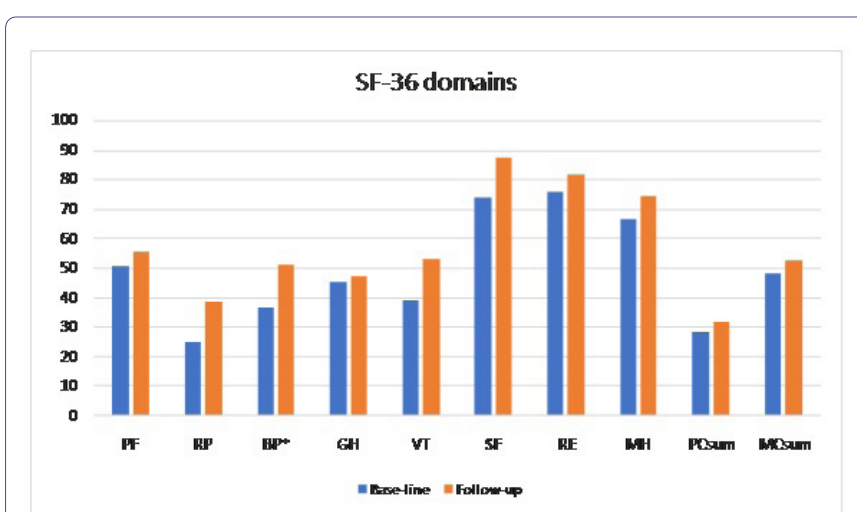

Figure 2: Comparison between base-line and follow-up concerning the SF36 domains in participants $(n=11)$ in the study group.

$\mathrm{PF}=$ Physical Function; RP=Role Physical; $\mathrm{BP}=$ Bodily Pain; $\mathrm{GH}=\mathrm{Gener}$ al Health; VT=Vitality; $\mathrm{SF}=$ Social Function; RE=Role Emotional; $\mathrm{MH}=$ Mental Health; PC sum=Physical Component Summary; MC sum=Mental Component summary.

Score 0 indicated the worst and score 100 the best condition for SF-36 domains.

Significance level $\mathrm{p}<0.05$ is presented as *

After the intervention period three women joined a strength training group and one woman joined a balance training group at the PHCC. Other participants continued their physical activity by regular walks and home training exercises.

\section{Discussion}

The lack of a "fracture coordinator" was obvious in the present study, as it was hard to recruit participants with a fragility fracture to the Osteoporosis school activities from other PHCCs than the one in 
Vadstena. The use of coordinated, multi-disciplinary models of care for secondary fracture prevention is recommended by the International Osteoporosis Foundation (www.iofbonehealth.org/capture-fracture) [38]. The power of the present pilot study was weak, as the number of appropriate participants was small and there was not either any control group. Other concepts of structuring an Osteoporosis school may be better than the present school. A larger randomized controlled intervention study with an Osteoporosis school is planned to start in 2018 and will be issued from the regional Osteoporosis unit with restricted inclusion criteria such as diagnosed osteoporosis and vertebral fracture in persons aged over 60 years. Several Swedish health care regions have implemented the FRAX ${ }^{\circledR}$ tool to find out high-risk patients in order to give adequate medical treatment and rehabilitation for the prevention of a secondary fracture. The use of FRAX ${ }^{\circledR}$ into physical therapist practice is a rather new activity. Educating about patients' absolute fracture risk may lead to improved exercise motivation and adherence. However, questions on risk factors such as physical inactivity, propensity to fall, and height loss are not included in the FRAX algorithm model and should be added, when meeting patients in the clinic [39].

The Osteoporosis school was appreciated amongst the women in specific the exercise training sessions, which they told us were the best part of the school. A qualitative study previously confirmed that professionally supervised specific back exercise training may bring benefits to everyday life, increase well-being and quality of life in elderly women with vertebral fractures [40]. Supervised exercise training sessions for bone health and balance performance could be recommended to persons suffering from osteoporosis $[23,27,30,41$ 43]. The back-straightening ability was improved in the present study, which may mean better back muscle function [27]. Estimated pain decreased amongst the participants, which is in accordance with training studies designed for elderly women with osteoporosis and fractures with exercise sessions 45-60 minutes 2-3 times per week for 2.5-6 months [23,41-43]. The improvement in the SF-36 bodily pain domain agrees with a training study for four months [41]. A tendency towards improved balance performance was found in tandem walking forwards in spite of the few scheduled training sessions. In a training study for women with osteoporotic vertebral compression balance performance was improved after exercising two times a week for three months [42]. Five women in the present Osteoporosis school did not manage to stand on one leg with the eyes open for 10 seconds or more, which may mean about 2.6 times increased hip fracture risk according to a study with Swedish elderly women [44]. Mean values for hand grip strength $(19.6 \mathrm{~kg}$ in the dominant and $17.6 \mathrm{~kg}$ in the non-dominant hand) amongst the participants in the present study corresponded to normative mean values in American women aged 75 years and over [14].

Personal guidance, encouragement, and advice on adequate physical activity are very important to improve bone health, muscle function and balance in elderly women with osteoporosis and fragility fractures [45-46]. The international physical activity guidelines for public health recommend at least 150 min of moderate intensity distributed amongst 5-7 days a week, such as brisk walks for all adults $[47,48]$. However, elderly women with osteoporotic related fractures should not be forced to walk too fast due to an increased risk of falls [49]. There is a lack of well-designed studies evaluating the effect of education and physical exercise training in women with established osteoporosis [50,51]. Osteoporosis and fracture may have a profound impact on physical function and everyday activity. Thus, healthcare professionals and persons with osteoporosis would benefit from more information on how treatments impact patients' physical function and everyday activity, to optimise treatment decisions and to improve compliance and persistence with treatment to prevent future fractures [52].

\section{Conclusion}

This pilot study with an Osteoporosis school showed good compliance with decreased pain and improved back-straightening ability in older women with fragility fractures in their intention to become healthier by increased physical activity.

\section{Acknowledgement}

The study received financial support from Östergötland County Council.

\section{References}

1. Reginster JY, Burlet N (2006) Osteoporosis: a still increasing prevalence. Bone 38: 4-9.

2. [No authors listed] (1991) Consensus development conference: prophylaxis and treatment of osteoporosis. Am J Med 90: 107-110.

3. [No authors listed] (1994) Assessment of fracture risk and its application to screening for postmenopausal osteoporosis. World Health Organ Tech Rep Ser 843: 1-129.

4. Kanis JA, Johnell O, De Laet C, Jonsson B, Oden A, et al. (2002) International variations in hip fracture probabilities: implications for risk assessment. J Bone Miner Res 17: 1237-1244.

5. Svedbom A, Hernlund E, Ivergård M, Compston J, Cooper C, et al. (2013) Osteoporosis in the European Union: a compendium of country-specific reports. Arch Osteoporos 8: 137.

6. Kanis JA, Odén A, Johnell O, Jönsson B, de Laet C, et al. (2001) The burden of osteoporotic fractures: a method for setting intervention thresholds. Osteoporos Int 12: 417-427.

7. Hernlund E, Svedbom A, Ivergård M, Compston J, Cooper C, et al. (2013) Osteoporosis in the European Union: medical management, epidemiology and economic burden. Arch Osteoporos 8: 136.

8. Kanis JA (2008) Assessment of osteoporosis at the primary health care level. World Health Organization Collaborating Centre for Metabolic Bone Diseases, University of Sheffield, London, UK.

9. Mundy G (1998) Bone remodeling and mechanisms of bone loss in osteoporosis. In: Meunier PJ (ed.). Osteoporosis: diagnosis and management, Taylor \& Francis, London, UK. Pg no: 17-35.

10. Xu W, Perera S, Medich D, Fiorito G, Wagner J, et al. (2011) Height loss, vertebral fractures, and the misclassification of osteoporosis. Bone 48: 307-311.

11. Siminoski K, Warshawski RS, Jen H, Lee K (2006) The accuracy of historical height loss for the detection of vertebral fractures in postmenopausal women. Osteoporos Int 17: 290-296.

12. Morfeld JC, Vennedey V, Müller D, Pieper D, Stock S (2017) Patient education in osteoporosis prevention: a systematic review focusing on methodological quality of randomised controlled trial. Osteoporos Int 28: 1779-1803.

13. Antonelli-Incalzi R, Pedone C, Cesari M, Di lorio A, Bandinelli S, et al. (2007) Relationship between the occiput-wall distance and physical performance in the elderly: a cross-sectional study. Aging Clin Exp Res $19: 207-212$.

14. Mathiowetz V, Kashman N, Volland G, Weber K, Dowe M, et al. (1985) Grip and pinch strength: normative data for adults. Arch Phys Med Rehabil 66: 69-74. 
15. Grahn Kronhed AC, Möller C, Olsson B, Möller M (2001) The effect of short-term balance training on community-dwelling older adults. JAPA 9: 19-31.

16. Albertsson DM, Mellström D, Petersson C, Eggertsen R (2007) Validation of a 4-item score predicting hip fracture and mortality risk among elderly women. Ann Fam Med 5: 48-56.

17. Ware JE, Sherbourne CD (1992) The MOS 36-Item Short-Form Health Survey (SF-36), I: conceptual framework and item selection. Med Care 30: $473-481$.

18. Sullivan M, Karlsson J, Ware JE Jr (1995) The Swedish SF-36 Health Survey - I. Evaluation of data quality, scaling assumptions, reliability and construct validity across general populations in Sweden. Soc Sci Med 41: 1349-1358.

19. Hallberg I, Rosenqvist AM, Kartous L, Löfman O, Wahlström O, et al. (2004) Health-related quality of life after osteoporotic fractures. Osteoporos Int 15: 834-841.

20. Coons SJ, Rao S, Keininger DL, Hays RD (2000) A comparative review of generic quality-of-life instruments. Pharmacoeconomics 17: 13-35.

21. Persson LO, Karlsson J, Bengtsson C, Steen B, Sullivan M (1998) The Swedish SF-36 Health Survey II. Evaluation of clinical validity: Results from population studies of elderly and women in Gothenburg. J Clin Epidemiol 51: 1095-1103.

22. Andersson S, Arnér S (1991) Acute pain. Studentlitteratur. Lund: Benzon Pharma AB.

23. Malmros B, Mortensen L, Jensen MB, Charles P (1998) Positive effects of physiotherapy on chronic pain and performance in osteoporosis. Osteoporos Int 8: 215-221.

24. Sinaki M (2012) Exercise for patients with osteoporosis: management of vertebral compression fractures and trunk strengthening for fall prevention. PM \& R 4: 882-888.

25. Chien M, Yang RS, Tsauo JY (2005) Home-based trunk-strengthening exercise for osteoporotic and osteopenic postmenopausal women without fracture -a pilot study. Clin Rehabil 19: 28-36.

26. Hongo M, Itoi E, Sinaki M, Miyakoshi N, Shimada Y, et al. (2007) Effect of low-intensity back exercise on quality of life and back extensor strength in patients with osteoporosis: a randomized controlled trial. Osteoporos Int 18: 1389-1395.

27. Bergström I, Bergström K, Grahn Kronhed AC, Karlsson S, Brinck J (2011) Back extensor training increases muscle strength in postmenopausal women with osteoporosis, kyphosis and vertebral fractures. Adv Physiother 13: 110-117.

28. Paolucci T, Morone G, Iosa M, Grasso MR, Buzi E, et al. (2014) Efficacy of group-adapted physical exercises in reducing back pain in women with postmenopausal osteoporosis. Aging Clin Exp Res 26: 395-402.

29. Ball J, Cagle P, Johnson BE, Lucasey C, Lukert BP (2009) Spinal extension exercises prevent natural progression of kyphosis. Osteoporos Int 20: 481-489.

30. Halvarsson A, Franzén E, Ståhle A (2015) Balance training with multitask exercises improves fall-related self-efficacy, gait, balance performance and physical function in older adults with osteoporosis: a randomized controlled trial. Clin Rehabil 29: 365-375.

31. Gillespie L, Robertson MC, Gillespie WJ, Sherrington C, Gates S, et al. (2012) Interventions for preventing falls in older people living in the community. Cochrane Database Syst Rev CD007146.

32. Karlsson MK, Magnusson H, von Schewelov T, Rosengren BE (2013) Prevention of falls in the elderly--a review. Osteoporos Int 24: 747-762.

33. Papaioannou A, Adachi JD, Winegard K, Ferko N, Parkinson W, et al. (2003) Efficacy of home-based exercise for improving quality of life among elderly women with symptomatic osteoporosis-related fractures. Osteoporos Int 14: 677-682.

34. Sinaki M, Mikkelsen BA (1984) Postmenopausal spinal osteoporosis: Flexion versus extension exercises. Arch Phys Med Rehabil 65: 593-596.
35. Leijon ME, Bendtsen P, Nilsen P, Festin K, Ståhle A (2009) Does a physical activity referral scheme improve the physical activity among routine primary health care patients? Scand J Med Sci Sports 19: 627-636.

36. Grahn Kronhed AC, Möller M (1998) Effects of physical exercise on bone mass, balance skill and aerobic capacity in women and men with low bone mineral density, after one year of training - a prospective study. Scand J Med Sci Sports 8: 290-298.

37. Grahn Kronhed AC, Salminen H (2017) Long-term effects of a ten-year osteoporosis intervention program in a Swedish population - a cross-sectional study. Prev Med Rep 5: 295-300.

38. Javaid MK, Kyer C, Mitchell PJ, Chana J, Moss C, et al. (2015) Effective secondary fracture prevention: implementation of a global benchmarking of clinical quality using the IOF Capture the Fracture ${ }^{\circledR}$ Best Practice Framework tool. Osteoporos Int 26: 2573-2578.

39. Perry SB, Downey PA (2012) Fracture risk and prevention: a multidimensional approach. Phys Ther 92: 164-178.

40. Qvist N, Bergström I, Grahn Kronhed AC, Karlsson S, Forss A (2011) Empowering the fragile body: experiences of a back muscle group training program in postmenopausal women with vertebral fractures. A qualitative interview study. Adv Physiother 13: 63-70.

41. Grahn Kronhed AC, Hallberg I, Ödkvist L, Möller M (2009) Effect of training on health-related quality of life, pain and falls in osteoporotic women. Adv Physiother 3: 154-165.

42. Bergland A, Thorsen H, Kåresen R (2011) Effect of exercise on mobility, balance, and health-related quality of life in osteoporotic women with a history of vertebral fracture: a randomized, controlled trial. Osteoporos Int 22: 1863-1871.

43. Gold D, Shipp K, Pieper C, Duncan P, Martinez S, et al. (2004) Group treatment improves trunk strength and psychological status in older women with vertebral fractures: Results of a randomized clinical trial. J Am Geriatr Soc 52: 1471-1478.

44. Lundin H, Sääf M, Strender LE, Nyren S, Johansson SE, et al. (2014) One-leg standing time and hip-fracture prediction. Osteoporos Int 25: 1305-1311.

45. Dohrn IM, Ståhle A, Roaldsen KS (2016) "You Have to Keep Moving, Be Active": Perceptions and Experiences of Habitual Physical Activity in Older Women With Osteoporosis. Phys Ther 96: 361-370.

46. Halvarsson A, Ståhle A, Halén C, Skavberg Roaldsen K (2016) "Better safe than sorry": a qualitative content analysis of participant's perspectives of fall-related concerns and balance in older women with osteoporosis after balance training. Disabil Rehabil 38: 796-802.

47. [No authors listed] (2009) Physical Activity Guidelines Advisory Committee report, 2008. To the Secretary of Health and Human Services. Part A: executive summary. Nutr Rev 67: 114-120.

48. FYSS (2017) Fysisk aktivitet i sjukdomsprevention och sjukdomsbehandling. Läkartidningen förlag AB.

49. Ebrahim S, Thompson PW, Baskaran V, Evans K (1997) Randomized placebo-controlled trial of brisk walking in the prevention of postmenopausal osteoporosis. Age Ageing 26: 253-260.

50. Giangregorio LM, MacIntyre NJ, Thabane L, Skidmore CJ, Papaioannou A (2013) Exercise for improving outcomes after osteoporotic vertebral fracture. The Cochrane Library Issue.

51. Giangregorio LM, Papaioannou A, MacIntyre NJ, Ashe MC, Heinonen A, et al. (2014) Too fit to fracture: exercise recommendations for individuals with osteoporosis or osteoporotic vertebral fracture. Osteoporos Int 25: 821-835.

52. Kerr C, Bottomley C, Shingler S, Giangregorio L, et al. (2017) The importance of physical function to people with osteoporosis. Osteoporos Int 28: 1597-1607. 